\title{
Henning Nфlke
}

\section{The Logic and Pragmatics of Connectors ${ }^{1}$}

\begin{abstract}
A long tradition has used logic for the description of connectors and other linguistic formators. It is argued in this article that this in fact is not a good idea. After an analysis of the meaning of connectors, as they have been studied in linguistics, their formal function is scrutinized. It is shown that one ought to distinguish their iconic function, which is the only one studied by linguists so far, from their deictic function, which controls the search for their arguments. This result permits us to address the crucial question: Why has logic acquired such a predominant place in the study of natural connectors? What is the basis for this way of viewing their function? It is finally shown how the insights obtained in this analysis can be exploited for the examination of the formal aspects of other linguistic items.
\end{abstract}

\section{Introduction}

Until recently, discussions about meaning have not paid much attention to those expressions which have no meaning, or at least no referential meaning in the usual sense. These expressions, which may be called syncategoremata, following the schoolmen, formators, following Charles Morris (1938), or logical words (e.g. Geoffrey Leech 1974)), have often been considered as contributing invariably to the whole meaning of the sentence. They are held to be "internal to linguistics" (Leech 1974, 161), their function being totally independent of pragmatic concepts like discourse situation, background knowledge etc. Accordingly, they are mostly analysed in terms of logic and the composition axiom (cf. Frege 1952). Thus the meaning of connectors, on which I shall concentrate in this article, is seen by the mainstream of research as being determined by combinatorial rules applying to the truth value of atomic elements.

From a historical point of view, this is a surprising situation. Indeed,

1 This article is a slightly updated version of a part of a manuscript that I wrote in 1984 with Jean Widmer from Fribourg in Switzerland. Though it contains mainly the sections for which I was chiefly responsible, this text would not have been possible without the ideas and insights of Jean Widmer. Further, it has not been possible to pay sufficient attention to very recent developments of linguistic theory. In particular, it seems probable that the Relevance Theory developed by Dan Sperber and Deirdre Wilson (e.g. 1986) could well turn out to become of extreme interest for the kind of problems dealt with in this article. 
the symbolization of logic was not introduced by Aristotele owing to its advantages for calculating, but because it allowed a more stable representation of the kind of relations that were to be studied, i.e., it institutionalized a kind of abstraction. Now, if one considers these efforts, one may well wonder how logicians, and linguists, came to use uncritically the now well developed symbolic logic as a model for the function of connectors in natural languages, particularly since this logic was not formulated to explain natural languages, but rather to introduce cognitive dissociation from them ${ }^{2}$.

Admittedly, this state of affairs has changed during the last years in which much work has been done on some particular expressions without referential meaning. I shall refer especially to the work of the French linguist Oswald Ducrot and his colleagues, and occasionally to the recent development of Relevance Theory (cf. Sperber \& Wilson 1986). But even in this line of analysis, there is implicitly, or sometimes explicitly, the assumption that symbolic logic can be used as an unproblematic descriptive model for words like and, or and if...then. In the present article I will argue against this widespread conception. Logic is in fact a poor model for the description of (natural) connectors because the different aspects of meaning (one of which is the generic, or the formal aspect in the sense of formal logic) are always intimately related in natural language. That this is so is not only attested through the very tradition of logic touched upon above; it is also confirmed by the fact that logical combinations occur in cases where no explicit connector can be found. Thus, if one takes seriously the theoretical claim that the meaning of utterances is always dialogic, this dimension should show up also in the description of natural connectors. Further, since real communication always occurs by means of utterances, the time dimension of speaking should be dealt with. As we shall see, this dimension is central, as it offers the very scene for the inner temporal course of interpretation. In fact it plays a double role, since the time of production is necessarily linear, whereas the time of interpretation may anticipate or cycle back to previous points located during the time of speech production.

Consequently, I shall have to deal with essentially two questions: How can logic have been used as a model (i.e. what is the basis for this way of viewing the function of natural connectors), and how are these logical formal aspects related to the speech situation?

2 Actually, as we shall see, some aspects of the natural function of connectors still remain intact even in formal logic. 
In order to approach an answer to these two questions I will try to give a systematic account of the behaviour of connectors. It is not my intention to produce analyses of particular connectors; what I want to do is to present a model for their general function. My approach is clearly interpretative, as its focus is on interpretative work, assuming tacitly that the production side anticipates just this work. As a consequence, I shall, against usual practice, move from pragmatics to syntax instead of the other way around. Thus against the Saussurian tradition, I do not treat the language system as self-contained. I shall in fact allow for some kind of embedded pragmatics. This procedure will enable me to show a number of structuring aspects which logic in its standard forms is not able to account for, and I shall conclude that logic is a poor model even for the description of these "logical words".

\section{The meaning of connectors}

Before I look at how some linguists have treated connectors I will have to consider the relation between the meaning of referential terms and the meaning of logical words. After this I will describe how this meaning is internally dialogic by presenting briefly the polyphonic theory developed by Oswald Ducrot.

\subsection{The function of formators}

The first distinction aims to conceptualize the relations between aspects of meaning which originate both in explicit linguistic tokens and in the utterance situation, especially in the following features of this situation: the seriality of speech production, the inner-temporal course of interpretations and the relevant identities of communicators (cf. 2.2.). One may conceptualize these aspects of meaning by using a distinction suggested by R. Ingarden (1929): the distinction between material, formal and modal aspects of meaning. I do not take this distinction in an ontological sense as Ingarden did. For me the material aspect of meaning concerns the fact that any utterance is talking about some universe of discourse, its material. This aspect draws on conventionalized, as well as on more vernacular knowledge, according to the kind of speech. The formal aspect concerns the aspects generally highlighted by logic (quantification, inferences etc.) as well as distinctiveness and objectivity. The modal aspect of meaning has to do with the various ways we speak. I shall touch on this aspect when introducing the polyphonic theory in 2.2. Here I want to consider some relations between material and formal aspects, limiting my considerations to those relations which are relevant for the questions of logical connectiveness in the usual sense. 
The sense of expressions in an utterance is used as material for interpreting what is said (the material meaning) not only on the basis of lexemes, syntactic location and rules, but as something used by the speaker to tell more than his words can say - for "speaking between the lines". What you say is only a "gloss" of what you want to tell, since what is told always involves an indefinite amount of world knowledge, a point stressed by John R. Searle (1978; 1980), and many years earlier by the ethnomethodologists (Garfinkel 1967, 24-31; Garfinkel \& Sacks 1970). This world knowledge is always knowledge about a practical world in the sense that it is a world known, produced and organized by the same people who talk about it (thus reproducing and sometimes even increasing world knowledge). That is to say it is a structured knowledge, and its structures are implicitly used in order to interpret what is told from what is said ${ }^{3}$. Thus we may find many examples of implications, exclusions etc. which are used implicitly, without connectors. Examples can be found in Leech $(1974,162)$. Leech notes also that many logical words include non-logical elements designating time, place, movement, person etc. ${ }^{4}$.

Thus we may ask, as Leech does: Why does language use formators at all?

Leech answers this question by arguing that "these elements greatly increase the power of human thinking, because they are instruments with which we can explicitly manipulate the categories and relationships of meaning which exist on the level of semantic representation" (ibid. 163). This functionalist argument seems to imply that the formators are introduced just because they are useful, and it does not explain how they function. In this connection Roland Posner (1980, 196-197) makes a very useful remark. He shows that the strength of what he refers to as a connexity suggestion depends on the degree of embedding of the clause concerned in the entire sentence, or on how high the verb of propositional attitude is in the structure of the sentence. Since he understands suggestions as pragmatically induced, this leads him to the observation that a higher degree of explicitness increases the literal (semantic) meaning and cancels suggestions. I will express this in my framework by saying that

3 This idea is in fact the backbone of the Relevance Theory developed by Sperber \& Wilson (1986).

4 This connection between logical words and references to places, times and persons i. e. the references of indexical terms, should cause no surprise in natural language, and interestingly, we find the same connections in modal logic. 
explicit logical work takes precedence over logical work which is implicit in the interpretation of meaning, and this is exactly why formators are used. That the logical features of the formators take precedence over the implicit logical operations is not to say that they cancel several logical operations. The cancellation is selective. Thus and can seem to carry relations of time, place consecutions etc. (cf. Posner 1980), which are in fact not grounded in the formator, but in the interpretation of meaning. Leech (1974) is right in implying that meaning, interpretation and logical operations are inseparable. This account also explains why the "literalness" of formators increases the more deeply embedded they are: Each new formator cancels implicit operations which are replaced by the new operations which are run through the formators. To say "new operations" is to say that natural discourse has a limit for how many formators should be used. This fact is nicely explained by the Principle of Relevance from Relevance Theory (Sperber \& Wilson 1986, 158) ${ }^{5}$. Since new operations cause extra effort of interpretation they may only be permitted if this extra effort is counterbalanced by greater contextual effect. Otherwise they decrease the degree of relevance. In fact there seems to be even more involved. The usual formators (and the logical functors) seem to carry specific kinds of operations, viz. operations that can be formalized, i.e. drawn out of the mist of meaning interpretation. This accounts for the development of sentence formators as "pure" logical words in contrast with phrasal formators which tend towards being more mixed up with material meaning, with the exception of negation. This fact suggests that these formators do not handle "word meaning" but rather syntagmatically determined meaning. The pragmatic system I shall suggest in the second section of this article exploits this hypothesis which, and I would like to stress this fact, forces us ultimately to reject Frege's composition axiom as a method.

\subsection{The theory of polyphony}

The main problem with Leech's description of formators seems to be that his approach analyses meanings independently of any context (1974, 30ff). Now, if I am right in believing that most formators are mixed up with material meaning I have to introduce the notion of context into the system in a principled way. Of course I do not have to analyse the concept of context itself, but from a theoretical point of view it seems very

5 "Every act of ostensive communication communicates the presumption of its own optimal relevance". 
important to maintain a clear distinction between the sense of the expressions, i.e. out of any context, and their meaning as part of the utterance act, i.e. their occasional meaning in context.

Exactly this distinction is the backbone of the theoretical work of Oswald Ducrot (cf. for instance Ducrot 1980a;b). He and his students have worked out a theory of polyphony and argumentation which turns out to be particularly suitable to treat the function of connectors in natural language. Ducrot starts by saying that meaning (Ducrot: "le sens") is the semantic description of the utterance. We must thus talk of an actual meaning, which depends both on the utterance act including its location (the utterance situation) and on the content of the sentence. To the sentence conceived of as an abstract object of linguistics, we attach a semantic description which we call the sense (Ducrot: "la signification"). Ducrot argues, as I do, that the linguistic sense is totally different in nature from that of the utterance meaning. This sense has to be seen as a set of conditions or instructions for the interpretation of the meaning, or as a set of strategies which the interpreter must follow. Let me stress this point: The sense is not a sort of minimal or incomplete meaning which will be completed during the interpretation process. Note that this approach offers a solution to the literal meaning problem (cf. Searle 1980). There simply is no literal meaning in the naive sense, since all meaning depends on context. On the other hand, we have the sentence sense which, in a certain sense, seems to account for the intuition behind all this pretheoretic talk of literal meaning. Only — and this is exactly the crucial point - the sentence sense is not a meaning in the technical sense of this term.

Now in a certain sense the meaning of the utterance signal (l'"énoncé") is a description of the locutionary act (l'"énonciation") 6 . The utterance signal shows the locutionary act as communicating a certain number of points of view on different states of affairs, propositional contents and so on. The basic idea behind the polyphonic theory is actually that every utterance may involve several such "embedded" discourses7. More ex-

6 Lyons (1977:26) proposes the terms 'utterance signal' and 'utterance act' in order to capture this important distinction between the utterance seen as an act (l'énonciation) or as the result of this act (l'énoncé). As the subtle difference between utterance act in this sense and locutionary act does not matter for my purpose I have opted for the more established term here.

7 As I will use the polyphonic theory only as sort of a conceptual framework in this article, I shall content myself with presenting the main ideas behind it. For a more thor- 
actly, the meaning of the utterance consists of the superposition of a certain number of elementary discourses. The important point is that other points of view than the speaker's may be present in this way, and that these individual points of view may even be marked or indicated at the sentence level, i.e. by the linguistic material. The negation is the canonical example:

\section{(1) This wall is not white.}

One has a clear intuition of the simultaneous presence in this utterance of two incompatible points of view. In fact, the use of the negation seems to be explained by a desire of the speaker to show that somebody probably thinks (or might have thought) that the wall is actually white, which is not the fact according to the speaker. To formalize this observation we will say that the negation (not) induces a polyphonic structure into the sentence consisting of two (incompatible) viewpoints $\mathrm{v}_{1}$ : 'This wall is white' and $\mathrm{v}_{2}$ : ' $\mathrm{v}_{1}$ is wrong' 8 . Empirical arguments for the presence at the sentence level of these two distinct viewpoints are to be found in the study of the possible continuations of (1):

(2) a. [(1)], which you know very well.

b. [(1)], which my neighbor thinks.

c. [(1)], on the contrary.

Whereas a. connects to $\mathrm{v}_{2}, \mathrm{~b}$. and c. take $\mathrm{v}_{1}$ as their starting point. It is very interesting to note that the speaker may connect directly to a viewpoint from which he explicitly dissociates himself. That is the case in (2b.) and (2c.). Incidentally we notice that whereas we know from the utterance of (1) who is responsible for $v_{2}$ (that is the speaker), we cannot tell who is associated with the other viewpoint $\left(\mathrm{v}_{1}\right)$. All we know is that it is not the speaker ${ }^{9}$, and it becomes a central concern of the interpretati-

ough introduction I refer to Ducrot (1984) or Nølke (1989). In the latter work, I have outlined an elaboration of the theory which aims at anchoring it in the formal structure of language.

8 In the first versions of the theory, Ducrot talked about (illocutionary) act instead of viewpoints. This explains the perhaps somewhat unfortunate name of polyphony. In fact inasmuch as it is a question of acts we may say that several voices are speaking at the same time in the utterance, hence the term polyphony. Today Ducrot prefers the term primitive acts, but as even this term seems a little odd, since what we try to capture is certainly not an act in the normal sense of the word, I prefer the more neutral term viewpoint (see Nølke 1989 for a longer terminological discussion).

${ }^{9}$ In marked context it may even be a (former) instance of the speaker as in "Well, in fact the wall is not white". 
on process to try to anchor this other viewpoint, even though this relation, of course, may be left unspecified.

Let us introduce a little terminology in order to capture these nuances. I would like to emphasize that all these concepts are located at the sentence level. The polyphonic structure is in fact considered as a property of language inscribed in the sentence. I shall use the following definitions:

The speaker (le "locuteur") is the producer of the locutionary act according to the utterance. He may leave traces in the sentence, e.g. the pronoun I.

The recipient (l'"allocutaire") is the individual for whom the utterance is produced. The second person pronouns are among the traces he leaves in the sentence.

The discourse individuals (the DI) are the individuals who can be held responsible for the viewpoints expressed in and by the utterance.

Besides the speaker and the recipient, several other DIs may be introduced during the discourse process or may be already present in the universe of discourse, i.e. being part of the world knowledge (cf. 2.1.). Even vague groups of individuals may be DIs in this technical sense. Thus, the DI responsible for a presupposed viewpoint is a set of members of the speech community supposed to share the presupposed viewpoint (according to the utterance containing the presupposition) ${ }^{10}$. Of course, as we shall see, it is now a crucial part of the interpretation process to establish the relations between the DI and all the expressed viewpoints, which is tantamount to uncovering the relevant identities of communicators.

This theory is of importance for the analysis of connectors since the scope of natural formators is not restricted in the way logical functors are. In particular, there is normally not a fixed range of syntactic elements which can serve as arguments for them. It is more a fixed combination of whatever is found. Thus Posner $(1980,191)$ proposes the following example as a case of contradiction based upon the fact that conjunctivity is a semantic feature of and:

10 Note that contrary to Ducrot I no longer talk about "énonciateurs" as "senders of the viewpoints". In so far as a viewpoint apparently never has "targets" specified at the sentence level it seems to me that it is unnecessary to talk at this level of a sender and a recipient of the viewpoint. Of course this decision is a consequence of the abandonment of the dynamic conception of the viewpoints which underlies the term 'act'used by Ducrot. 
(3) Peter married Annie and Annie had a baby: the complete sentence is true, but one of its constituent sentences is false.

Although it is true that conjunctivity is a semantic feature of and (I shall say an iconic feature, cf. 3.3.), it does not follow that (3) is necessarily a contradiction for natural speakers since they may take and as joining not two propositional contents but two utterance acts, thus hierarchizing the whole sentence in a distinct way ${ }^{11}$. This interpretation may appear for example when (3) is part of a guessing game. Or consider the following trivial example:

(4) I will speak about formators, or logical words.

(4) may be interpreted as meaning that I will speak alternatively of one or the other, but the usual interpretation is that I will speak of what can be called formators, or can be called logical words. The polyphonic structure of the whole sentence is in this case something like:

$$
\begin{aligned}
&(4 ') \mathrm{v}_{1} \\
& \mathrm{v}_{2} \text { : ' } \mathrm{I} \text { is called formators' } \\
& \mathrm{v}_{3}: \text { ' } \mathrm{X} \text { is called logical words' }
\end{aligned}
$$

and or has as arguments the two implicit (embedded) viewpoints $\mathrm{v}_{2}$ and $\mathrm{v}_{3}{ }^{12}$.

\subsection{Connectors in linguistics}

I have already had the opportunity to mention some of the proposals and ideas due to Leech (1974) and Posner (1980). Posner's analysis of and will be discussed in more detail later (in 4.4.). Here I shall briefly survey other linguistic literature on the subject.

In the work of traditional linguists we find many good remarks on the "meaning" of connectors but rarely any really systematic descriptions. Sydney Greenbaum (1969) may be mentioned as a remarkable exception. He concentrates, however, on syntactic features in the classical structuralist sense, and his semantic analysis remains on a purely descriptive level. What we may retain from his work is that many of the semantic features he uncovers cut across the syntactic classes he operates with, a

11 Of course natural speech does not sustain systematically the theoretical distinction I have introduced between 'sentence' and 'utterance'. In theoretical terms only utterances can be true or false. Sentences merely have truth conditions.

12 The speaker accepts these two viewpoints without associating himself with them. See Nølke (1989) for an analysis of the different possible relations between the DI and the viewpoints. 
fact which should not astonish us when we consider the extent to which semantic interpretation is dependent on logic (cf. 2.1.).

A more systematic description of connectors might be expected to be found in the general linguistic theories. However, in the Chomskyan Transformational Grammar, for instance, we find something about quantifiers and negation, and J.R. Ross (1986) studies some general properties of coordination, but the constituting properties of the connectors are hardly ever examined.

Not surprisingly it is the more logically oriented semantic theories (e.g. Montague grammars) that offer the most systematic accounts. The basic idea here is that the connectors should be translated into logical functors ${ }^{13}$. The problem is now how to deal with the obvious differences in meaning and function between the linguistic and the logical expressions (Posner 1980; Givón 1982). The solutions based on the Gricean maxims do not give any systematic description of these words, mainly because they pay very little attention to the serial, temporal dimension of discourse. In fact, the Gricean rules give one a good (although unsystematic) way of describing what happens, but as an interpretative gloss which does not account for how or why this orderliness is produced, if we are not to take his rules as norms, a move which would be still more problematic. The recent model semantic approaches (e.g. Barwise \& Perry 1983; Kamp 1981; Meulen 1983; Nef 1988) appear to be of no help here. They can be seen as attempts to explicate the background knowledge, and some well defined parts of it have actually been formalized. However, they consider the background knowledge as built up of atomic objects and their relations, and do not really take into account the temporal dimension of discourse, which is in fact, I shall argue, crucial for the understanding of how the connectors work.

The recently developed Relevance Theory seems much more promising. With its radical switch in the status of the notion of relevance, which in this theory becomes a constitutional property of language, it might well be able to give a proper account of the behaviour of connectors. In any case, it has already permitted some steps to be taken towards a systematic analysis of the so-called "discourse particles" which by and large correspond to the connectors. Thus Diana Blakemore (1987) has shown that discourse particles (and, but, after all, ...) function as constraints

13 See for instance Karolak (1988), who gives an excellent introduction to the general logical approach to linguistic connectors. 
working directly on the interpretation process (her so-called constraints on relevance) without interacting with the building up of the propositional content. Yet, so far it is hard to tell whether this new approach may ultimately bring new insights into the important role the temporal dimension plays in this connection.

Finally, I have myself argued elsewhere (Nølke 1990b) that two classes of connectors should be distinguished: the (genuine) synthetic connectors whose primary function it is to establish connexity, and the analytic connectors which, having another primary function, only indirectly induce this special type of semantic cohesion. However, as my main concern in this article is the study of the structure of the connector function, I shall disregard this difference below.

This brief survey of the linguistic literature on connectors seems to reveal a rather heterogeneous situation. Many detailed analyses have been suggested, but there does not exist any general study, and it seems that the more profound the analyses are the more heterogeneous they are.

On one point, however, most linguists seem to agree: There is somehow a narrow relation between the connectors and a "logical level", and in this sense connectors have a constant semantic function. But even if it is acknowledged that much logical work is performed without the explicit use of formators, no proper reasoning has ever been offered with respect to the relationship in a particular sentence between the connectors and the other parts of the sentence ${ }^{14}$.

\section{Functions of connectors}

The analysis of the formal aspects of meaning concerns quantification, the specification of reference, as well as what is called the logical relations among semantic units. Our model primarily tries to account for the expressions which have as their function to contribute to the establishment of semantic coherence (or cohesion).

\subsection{A case analysis}

In order to introduce my description of connectors, I shall point to some problems such a description must face by discussing the fairly

14 A typical remark from the linguist is that the connectors are characterized relative to the designators by their lack of referential function. I shall argue that not only is this false, but that there is also much more to the semantics (and pragmatics!) of the connectors than this connection with a "logical level". 
well-known expression but $^{15}$. Consider Lakoff's famous example:

(5) He is a republican, but honest.

A first interpretation of (5) can be formulated as follows: Take the segment preceding but to be $p$, and the segment after it, $q$, then (5) can be analyzed as " $p$ implies $r$ but $q$, and $q$ is non-r", where $r$ can be specified as "he is not honest". This is a very rough analysis, which could be brought under closer scrutiny by considering the world knowledge involved in the explication of $r$ (cf. 2.1.) and the kinds of viewpoints involved (2.2.). Whereas p may be bound to a single discourse individual, " $p$ implies $r$ " is presented as being the statement of a general opinion (something like "one says that republicans are not honest").

There are some obvious problems involved in this analysis. First the analysandum contains the analysed expression but. We might try to substitute and for but. In order to do this, and to avoid contradictions, we should quantify " $p$ implies $r$ ". The point, however, is to note that such a quantification was involved in this use of but, just as " $p$ implies $r$ " and " $q$ is non-r" were involved in the use of but in (5). In other words, the buts in the example and in the explanation are slightly different, an important point which should not astonish us as we go further in our analysis. Another point concerns "imply" which remains unanalysed. In this respect we might sharpen the analysis by adopting Ducrot's concept of argumentative value. " $p$ implies $r$ " thus roughly means " $p$ is an argument for the conclusion $r$ ". The important difference is that whereas "imply" concerns the semantics of what is said, the argumentative value concerns the way of saying, a case of the connection between the 'what is said' and how it is said. Thus we are back at the communicative situation, since the argumentative value concerns an implicit viewpoint: 'republicans are not honest'.

A still more intriguing point is to consider that p could "imply" a lot of propositions, or none, e.g. as an answer to the question what is his political membership?. It is only after reading (or hearing) "but $q$ " that $p$ implies $r$. The same remarks are true of $q$. That is, $p$ and $q$ get new interpretations through their combination in " $p$ but $q$ ". Thus the whole is

15 I shall only discuss the use of but corresponding to the German aber (Spanish sino or Swedish men) and not the use which corresponds to sondern (pero/utan), nor the "exclusive use" we find in expressions like nobody but John. However, one should appreciate the interpretative ability of speakers who manage to make the difference routinely. Anscombre \& Ducrot (1977) studies the syntactic and semantic differences between the two uses of the French mais corresponding to the aber/sondern distinction. 
somehow more than the parts. This fact is hard to reconcile with the current logical approach which uses as a method Frege's composition axiom (cf. Nef 1988).

Still another aspect makes logic a poor model. Consider the following example:

(6) Everybody says that Peter knows a lot about French wine. Indeed you should have seen him when we did France last year. He told (...). But yesterday I served him a Turkish wine, and he thought it was a Bordeaux.

In (6) it is "Everybody says ... wine" and "yesterday ... Bordeaux" which are opposed. Actually $p$ (and sometimes $q$ ) may not only be located several utterances away, it may even be other kinds of semantic units than propositional contents of utterances. For that reason Ducrot $(1980 \mathrm{a}, 17)$ uses $X$ and $Y$ for the segments around $b u t$, and $p$ and $q$ for the semantic units which function as arguments. I shall come back to this point in the third section.

To sum up let me stress the crucial points: It is not $r$ and non- $r$ which are opposed by but, but the semantic units $p$ and $q$. However, to work out the opposition, the $\mathrm{r}$ has first to be searched for. This means that $q$ stands in opposition to $\mathrm{p}$, not on the sentence level, i.e. in the sense, but on the utterance level: First I said $p$ and now I say $q$. But is an articulation of speech production itself. It is therefore no wonder that the semantic units but is operating on can be from analytically distinct levels. In natural language connectors seem to be used with instructions governing the selection of their arguments in situ, a feature which is specifically missing in logic, where this is avoided through explicit rules governing operators and a standard format of distribution for the arguments.

\subsection{Pointing functions}

The observation that $X$ may not coincide with $p$ indicates that but is used with an instruction to look backwards in order to find some semantic unit which can serve as argument. Thus but is used "about" some set of expressions as far as they can be interpreted as arguments. It is of course not a referential function, since but is not a name, nor is it used in any metalinguistic sense. Its status could be described in classical logic as of a higher type than the expressions which serve as arguments. In natural language, this means that it is syntactically placed within segments of sentences at the same time as it works on them as an organizing and combinatorial device. It is organizing because it connects segments of discourse which otherwise would not be connected explicitly, and it is 
combinatorial as it requires a semantic operation. Inspired by C.S. Peirce's work in semeiotics (cf. Peirce 1960), I propose to speak here about pointing functions. I choose the term "pointing" because it conveys the idea that the connectors are about other parts of the same discourse, whose location is relative to that of the connector ${ }^{16}$.

Now, these discourse parts may be of very different kinds. A sentence or a whole section can begin with but, and one has to look for whole pieces of discourse, which may be another section, or even non-verbal behaviour (see 4.3.). The consequent, $q$, too, may not be verbalized as in $\mathrm{He}$ is a republican, but ..., where the guessing game goes the other way round: you have to imagine not only $q$, but also $r$, and there is a specific open-endedness which is related to the kind of transformation but performs on the semantics of $p$.

But before we consider that aspect, we should notice that the pointing function is never random with respect to the locational instruction: $p$ always has to be found before but, and $q$ after it. "Before" and "after" are expressions which exhibit the linear, serial production of action and talk, i.e. the social organization of activities, the syntax, text structure, turn taking, etc., in which but is placed. Formators are not instructions about how to see or to act upon the world outside of language. They are instructions about language production as a proper activity in time and with its own time.

It should be emphasized that what I call the pointing function is in fact a locational rule, not the actually performed moves of interpretation. Thus, it may very well be the case that in order to locate $p$, as in example (6), we first have to hear $q$. This fact concerns what Garfinkel (1967, ch.3) calls the documentary method of interpretation: the method used by speakers which consists in retrospective and prospective use of items in order to see of which meaning they are a document, at the same time as this meaning serves as a device in order to interpret, and in our case to locate, appropriate items. Both rules, the pointing and the interpretative method, are only specified in situ, but the first one is specific for a given connector, whereas the second one is quite general as it is used for the interpretation of any social action. We thus find again the famous Grice-

16 Deictic might have been a better term, but there are at least two reasons for rejecting it. First Peirce himself confused deictic and referential functions (cf. Burks 1949), and second - and worse - the pointing function in question not only covers what is normally called deictic but also what is called anaphoric relations in present-day linguistics (e.g. Kleiber 1988). Therefore I needed to find a "neutral" term. 
an distinction between conventional and conversational implicatures (cf. Grice 1975).

\subsection{Iconic functions}

What I propose to call the iconic function of connectors is what led students of these expressions to propose logic as a model for their analysis (e.g. Montague 1974; Posner 1980). I use the term iconic for the operational aspect of connectors because "a great distinguishing property of the icon is that by the direct observation of it other truths concerning its objects can be discovered than those which suffice to determine its construction" (Peirce 1960, 279). This seems to me a good characterization of the general way in which expressions like but function: By introducing but between he is a republican and he is honest, you do not learn anything new about but, but a lot about the two sentences. This is a further reason for using Peirce's terminology, as it allows us to say that connectors are not symbols, since they are not full signs: they do not say anything about the world outside language; they are an essential resource for semantic units in their function as full signs ${ }^{17}$.

Posner $(1980,190)$ was right in emphasizing that the "raison d'etre of and lies in its combinatorial function and not in its connecting function". This remark may be generalized to the entire set of connectors. But then we are only speaking of their iconic function. Actually, Posner missed the pointing function of and. But he observed another interesting feature: The combination which is involved in the iconic function of the connectors does not necessarily have to apply to truth values. He noted that the same combination is obtained with "It's nice ... and ..." or "It's too bad that ... and ...". Thus, the combination is not specific with regard to the kind of value which is involved, nor, as we have seen, with regard to the location of the arguments, nor, as we shall see, to the syntactic category of its arguments. As to this last point, we observed in section 2.2. (example (3)) that it may even transform the previous hierarchization of a sentence. Notwithstanding all this variability, the iconic function is in some sense context-free (cf. 4.3.). Thus I have analysed the iconic structure of but (cf. 3.1.), and I have acknowledged the conjunctivity as a feature of and (2.1.). Therefore I agree with the criteria used by Posner (1980, 181; 198) that for a given interpretation of a connector, which includes the

17 This fact is nicely expressed in the framework of Relevance Theory, where the connectors are shown to "impose semantic constraints on relevance". See Diana Blakemore (1987). 
pointing work and its variability, the Gricean tests of variability, cancellability and non-detachability do apply and show the constant iconic features. I shall come back to this point in the last section about the dual character of connectors which are at the same time context-free and context-sensitive. But first I should justify in somewhat more detail my choice of terminology.

\subsection{Remarks on the choice of terminology}

One nice thing about our terminology is that it allows not only for the possibility that other expressions will have these two functions, but furthermore for an understanding of the symbolic function which is the core instruction for what is called the meaning of expressions. This last function is central for all designators ${ }^{18}$. The symbolic functions are the main resources for the material aspects of meaning. The articles and the quantifiers add formal specification to that function. On the other hand, the main function of the modal expressions, which normally have a symbolic function, is pointing and combinatorial. In fact, they have a range of syntactic influence which is as broad as that of connectors, although their iconic function is different, as it concerns the modality of the references. Last but not least this terminology makes it easier for us to point out and describe relations between logic and language.

\section{Logic and connectors}

As logic has often been used as a model for the description of designators and more specifically of connectors, which are simply translated into logical operators, it is important to discuss why this is not a good idea as a matter of course (4.1.), and to account for its plausibility (4.2.).

\subsection{Logic as a model}

I have already had the opportunity of hinting at certain problems this approach must face. One difficulty for the application of logic is the necessity to draw a distinction between the segments $X, Y$ etc. and the semantic units $p, q$ etc., which necessitates a thematization of the iconic function.

A further difficulty lies in the fact that connectors are not specific with regard to the kind of arguments they may have. Consider the following examples, drawn from Ducrot (1980a, 15):

18 The "categoremata" in the terminology of the schoolmen. 
(7) Peter is here, but John will not see him.

(8) Peter is here, but John should not know it.

Both utterances are susceptible to at least two different readings. (7) can be interpreted such that the implicit $r$ is thus John can meet him (an interpretation which shows nicely the retrospective procedure involved, since John was not mentioned before but). (8) can be interpreted such that the implicit $r$ is thus you could tell it to John. In these interpretations, for (7), $p$ is the fact that Peter is here, whereas for (8), $p$ is the fact that I tell you that Peter is here: the propositional content and the speech act, respectively. But we can easily imagine interpretations which are the reverse. Indeed for (7), $p$ can be the speech act, the whole utterance thus indicating that I, the speaker, do not approve of a meeting between Peter and John, and for (8) $p$ can be the propositional content ('That Peter is here in the neighborhood of John could lead you to believe that he should meet John, but this is not the case'). Thus, although but is in several instances an instruction to see an opposition between what has been said and what is said now, the relevant interpretation of the argument is bound to the occasion, depending upon elements of the communicative situation.

This leads us to two more differences between connectors and logical operators. First, logical operators are used in a language designed to exclude context dependency, and presupposing mainly logical competency. Of course this frame is itself a context built in a communicative frame. Logic is also communicative work, even if it consists in abstract semantics. But the fact that logic has to work out such a frame ought to prevent us from using it naively as a model for natural language, since its most apparent properties are designed precisely in order to avoid the most apparent properties of natural language, a fact which is acknowledged by the long tradition of complaints among logicians concerning the lack of precision, the confusion etc. of natural language. It is actually a discussion of these problems which led Grice to introduce his theory of implicatures (1975, 41-43). The fact is that just as logic tries to abstract away from the context of its production, natural language uses this context and organizes it, drawing upon elements of the setting and organizing it (cf. Widmer 1982) ${ }^{19}$.

This is part of the second difference. Although logical demonstrations are produced in a serial way, using spatial location as an ordering device

19 This fact is recognized and exploited in Relevance Theory, where 'contextual effect' is a key notion. 
both within and between formulas, their interpretation is strongly atemporal. The truth value of a formula does not depend on its location, but only on the explicit definitions and rules of the system. This is a main resource for the context independence alluded to above ${ }^{20}$. In natural language, interpretation is bound to the same time of reading/ listening, and this time is not excluded from semantics, on the contrary, time is part of the very production of meaning. Thus any but reinterprets the segment of speech which is selected as $p$. It is one of the aspects of the literal meaning problem that the definiteness of the interpretation of any utterance is dependent on the occasion, because it is only on a particular occasion that the utterance in question has a definite meaning. Consider the difficulties we have in following a logical demonstration without visual support. This is due to the fact that for such a demonstration we have to resort to the literal formulations, which we do not have to keep in our minds in ordinary listening. In listening to natural speech, the designators and the connectors collaborate to provide definite meaning in any context, but the action of the rules, and hence the meaning, depends on context.

The function of connectors as organizing devices making use of the time factor in speech production as well as the fact that they are not specific with respect to the kind of semantic units they organize apparently raise insuperable problems for a description using logic as a model. It therefore seems to be justified to try another approach which can handle these problems, and this is exactly the kind of properties the pointing function may treat, thus leaving, as we shall see, the "logic" aspects to the iconic function.

\subsection{Logic as a criterion}

It should be clear by now that I do not see logic, at least in its present standard form, as a good model for connectors. Nevertheless, there are obvious relations between natural connectors and logic. Peirce distinguished three types of icons: image, diagrammatic and metaphoric (1960, $277 \mathrm{ff}$ ). Image icons function through their own quality (firstness); photographs are examples. Diagrammatic icons show relations which are analogous to the structure of their objects (secondness). Connectors have such an iconic function since the moves on the utterance level are parallel to the combinatorial moves which are to be performed on the seman-

\footnotetext{
20 In this century logic was first limited to a pure calculus (e.g. Wittgenstein in the Tractatus). Later sematics was introduced because of empirical issues. But no pragmatics was embedded in logic.
} 
tic level, although the seriality of the first move may be altered in the transformation, as with or (cf. 2.2.). Peirce specified that there is a third kind of iconicity, the metaphorical one (thirdness), as a sign may represent something which shows parallelism to something else. This is the case of logic with regard to natural connectors. This relation may be used in the other sense in order to formalize part of the logical work performed in natural discourse. Indeed, if we take into consideration the fact that the literalness of connectors increases with their power measured by their degree of embedding (cf. 2.1.), we have a stepwise process from natural language to logic. Through embedding, the connectors not only cancel implicit logical work, but they also have to take into account embedded connectors. Thus we get connectors which are used more and more formally in the sense that the logical work performed with material meaning gets out of focus, the logical work of the connectors becoming conspicuous. Complete formalization takes place when there is a replacement of all material meaning by expressions which display only their pointing or "syntactic" properties. This step is taken through symbolization (e.g. pronominalization), where the expressions of natural language are replaced by expressions which display only their syntactic category (pronouns). As is well known, this step made the fantastic advances in logic and mathematics possible, but it also introduced a reified version of logic as a model of natural reasoning. By defining the logical operators with respect to the syntactic category of their arguments, and their location, the pointing function of these operators was made rigid and got out of focus, since it was a prerequisite for the study of their iconic functions. Thus the analogical application of operators on different kinds of semantic units was regarded as a nuisance, and not as an intrinsic feature of the use of operators in natural discourse. Yet it is very interesting to notice that such a "nuisance" could not be avoided totally even in logic. We will see below that and as it is used by logicians in the explication of a set makes use of the seriality of speech (4.5.). The core problem is how we have to understand the formality of connectors in natural discourse, their context-"freeness" and their context-sensitivity.

\subsection{Context-free/context-sensitive}

What is new in the description of connectors suggested in this article is the way in which it introduces the context. It therefore seems appropriate to have a closer look at the role the context actually plays.

I have distinguished the iconic function and the pointing function. The 
iconic function corresponds in a sense to the logical aspect of the function of connectors, and the construction of logical models may be seen as a reflexion of this function and nothing more. As such the iconic function is context-free. It consists in introducing a semantic structure into the interpretation, a structure made up of a (logical) relation with its arguments. Ducrot's analysis of French mais already discussed in 3.1. may illustrate this procedure. In order to interpret an utterance containing mais you will always have to find - independently of the actual context - exactly three semantic units $p, q$ and $r$, and to understand, not only that $p$ and $q$ are both true, but also that $p$ is arguing for the conclusion $r$, $q$ for non-r and the whole complex for non-r. The pointing function, now, is a set of instructions for filling the slots in the semantic structure (in our example $p, q$ and $r$ ). In this respect the pointing function, too, is contextfree (or formal), as it always implies the same searching procedure.

On the other hand, the search procedure is context-sensitive in at least two senses. First because it makes use of the linear format of the production of speech: $p$ must always be found in the context preceding but in time. To put it otherwise, but connects what has been said to what is going to be said, and it is thus bound to performance even though the temporal relation between $p$ and $q$ is stable.

The dependence on serialization may be even more crucial in cases where more than one but is at stake in an argumentation. Ducrot (1980b, 12) quotes a text from La Bruyère's Les caractères, which is built up of utterances of the type $p$ but $q$, and where the permutation of any two such pairs would change completely the meaning of the entire text ${ }^{21}$. This is due to the fact that the final conclusion $r$, which - in a sense - is the meaning, is deduced step by step, and thus depends directly on the time factor.

The pointing function is also context-sensitive in a more important sense. The semantic units $p, q$ and $r$ must fit into the structure imposed by the iconic function. As we have seen, but introduces a sort of reinterpretation of $p$ and $q$ in so far as it forces the interpreter to find a conclusion $r$ that fits into the imposed structure. In this sense, the conclusion $r$ (and non-r) is introduced into the interpretation of utterances by the connector but, and we may say (following Ducrot ibid., 12) that but "refers"

21 "Je vois un homme entouré et suivi: Mais il est en place. J'en vois un autre que tout le monde aborde: mais il est en faveur. Celui-ci est embrassé et caressé, même des grands: mais il est riche. Celui-la est regardé par tous avec curiosité: mais il est savant et éloquent. J'en découvre un que personne n'oublie de saluer; mais il est méchant." 
to this conclusion. Yet, the exact shape of $r$ depends strictly on the detected semantic units $p$ and $q$. But, as we have seen, $p$ and $q$ are by no means necessarily identical to the properties expressed in the utterances immediately preceding and following but. Not only may they (at least $p$ ) be located several utterances away, but they may consist of ontologically very different semantic types. The semantic units often derive from the propositional content of utterances, but they may as well derive from speech acts, and even from non-linguistic context. Consider (9):

(9) But what are you doing?

Text (9) can be a reaction to a physical action, which does not prevent us from analysing but in (9) just like in the former examples, only, $p$, this time, is a non-linguistic item, viz. an action. The corresponding French connector mais even permits both $p$ and $q$ to be non-linguistic. The utterance Mais! is quite common in French and is analysed by Ducrot as connecting two non-linguistic items.

To recapitulate: But is context-free with regard to the logical transformation (the iconic function) and with regard to the pointing function, which consists in searching for "fillers" of the slots in the semantic structure of its iconic function. It is context-sensitive in at least two respects:

- Since there is no standardization of the syntactic location of the "fillers", the pointing function depends on the seriality of speech.

- Since there is no standardization of the syntactic type of the "fillers", which may be propositions, utterance acts or non-linguistic parts of the joint activity, the search procedures can be accomplished only if the interpreter can find some "fillers" which make sense materially, at the same time as they fulfil the requirements of the iconic and pointing functions of but.

The logical work of but is therefore not detachable from the whole semantic and communicative work in principle, although it is so in each given case, as we saw from Posner's analysis. This last statement calls for a clarification of the degree to which connectors are formal.

\subsection{Formality of connectors}

The analysis of and may throw light on how connectors are sensitive even to the logical work performed on the basis of material meaning. First we may observe that the explicit use of and is not always required, the succession of the utterances warranting the conjunctive work to be performed. The succession of utterances can represent interconnectedness 
only if the described events can be seen as connected. This point is also maid by Posner $(1980,193)$ who calls this and other located connections connexity-suggestions. These connections are exactly the kind of connections which are worked out in the analysis of the material aspects of meaning (Sacks 1974; Widmer 1983). Now, it is always possible to cancel such suggestions, i.e. logical work performed on the basis of the elaboration of material meaning, since explicit connectors take precedence over implicit connections. That this does not necessarily imply a preference of the analyst for explicit logical work can be shown by looking at an example proposed by Posner (1980, 194ff):

(10)If Annie has married and has had a baby, grandfather will be happy.

If if and and were both truth functional in the logical sense, (10) would be true in the case where Annie has had a baby and has married, irrespectively of the temporal order of these events. This, indeed, is not a normal interpretation of (10). As Posner points out, the consequent clause (grand father will be happy) is (normally) only considered as true if Annie has first married and then has had the baby. So, he concludes, "the truth of the consequent clause is dependent here upon the realization not only of the literal meaning of the antecedent clause, but also of its successivity suggestion". Thus, he implies, you have to choose between the truth functionality of the and or of the if. This implication, however, holds only if you wish a literal meaning, and further if you confine the logical work to the explicit work of the connectors. If we take the semantic units together with the utterance acts in which they appear, and can also connect what Posner calls suggestions, i.e. semantic units arising from the interpretation of material meaning (in his terms, from the application of Gricean postulates). Thus, if we admit that (10) is used sincerely and with connexity and coherence, we can explicate (10) as "If Annie has married and then has had a baby, ..." or as "... a baby, and she had the baby after the marriage, ...". The fact that and is embedded in an ifclause does not foreclose the possibility of other logical work, since, as we said, the canons of logic are distinct from natural language; whereas the former try to control any operation, the latter tries to be as economical as possible. A fact that is nicely expressed in the fundamental axiom of Relevance Theory: "Try for the greatest possible effect at the least possible effort". Thus Posner's example and his interpretation of it shows nicely how we should acknowledge that and involves conjunctivity as its iconic function, but that we should not impose the standards of logical 
reading on the analysis of natural discourse, a point I have emphasized throughout this article.

In addition my analysis seems to throw light on the difference between and and but. Many linguists have proposed to analyze but as an and plus something more. Logically and and but should be equivalent, but but also conveys some pragmatic aspects. The intuition behind this conception is explicated in our framework. In the case of and, the logical relation introduced by the iconic function into the text is part of the more complex logical relation introduced by but. The interpretation of but requires the search for three arguments $p, q$ and $r$, and one part of the relation between these ones is ' $p \& q$ '. The other parts probably cannot be expressed by classical logic, and this fact may explain why they are felt as pragmatic.

\subsection{Extension of the analyses}

It should be rather obvious how the analysis can be extended to other linguistic connectors. It is well known from recent linguistic research that not only conjunctions may display connector functions. Greenbaum (1969) in fact discerned a class of adverbials in English which he calls the conjuncts. Like the genuine conjunctions, their function is to connect two (or more) utterances. It is true that this function is only indirect in the case of the analytic connectors (whereas the connector function of synthetic connectors is direct, cf. Nølke 1990b), but this fact falls outside the analysis of the connection itself.

We may differentiate at least three main types of connectors: additives, oppositives, and ordering connectors. The first of these classes includes expressions like yet, however, and on the other hand. Most of them would receive analyses similar to the one I suggested for $b u t^{22}$. The second class (the additives) includes expressions like furthermore, besides and likewise. These connectors rather resemble and. The analysis of the third class - the ordering conjuncts (finally, secondly, etc., ...) - may be more complicated because the iconic function would concern an indefinite range of arguments, i.e. the pointing function has an open field along a given list of possible arguments. Here again we are faced with the interesting problems posed by the logicians about the nature of etc., and, less known, the interpretation of formulas like "a \& b \& c \& ...", where $b$ is simultaneously the argument of the first and the second $\&$. Now, the logicians would avoid that problem by using parentheses, but

22 See e.g. Moeschler \& Spengler (1981) and Gettrup \& Nølke (1984) for the exact nature of the relations introduced. 
this can be done only when the list is finished, that is, meanwhile we use another device for interpreting the list. This device seems to take the variables not as syntactic expressions only, but also as expressions produced in a serial way - thus these $\&$ are not transforms of pure tokens, but of utterance acts, and it is the series of these acts which may be followed up by etc., or closed by finally. Even expressions like to put it otherwise, which involve a distinct viewpoint, or in short can be analyzed in the way suggested. Only in these cases the arguments are utterance acts, and not pure semantic units 23 .

I would finally like to point out a special class of expressions which have been considered as belonging to the connectors. I have in mind adverbials like even, only, particularly etc., which I have proposed to call the "paradigmatic adverbials" elsewhere (Nølke 1982; 1983). Their interpretation requires the introduction of a specific paradigm. Let us consider a simple (classical) example:

(11) Even Peter came to the party.

To understand (11), you have to grasp that other persons than Peter have come to the party. The interpretation of (11) thus involves a paradigm of propositions, and this fact is due to the presence of even. In the present framework we may say that the iconic function superimposes a structure $£(p, q, r)$ where $p$ is the actual proposition, $q$ an arbitrary member of the paradigm (only $q$ must be different from $p$ ), and $r$ a conclusion (in Ducrot's sense). Note that the shape of the paradigm is restricted by the syntax of even. To get an arbitrary member you have to change the nucleus (in casu 'Peter') with a member of the same conceptual paradigm (in casu another person who could be expected to come to my party). Now the relation $(£)$ is something like " $p$ is a stronger argument for $r$ than $q$ is". In our example it might be known from the situation (background knowledge) that Peter is not eager to go to parties, and then $r$ might be something like "My party was a great success" 24 .

We see that the basic principle in this analysis is quite analogous to the one we proposed for but. The paradigmatic adverbials are in effect (indirect) connectors according to the characterization given in the introduction, so this is as it should be.

23 Cf. Nølke (1990a) for an analysis of their French counterparts in the framework of Relevance Theory.

24 This analysis of even was first proposed by Jean-Claude Anscombre (1973) for French même. 


\section{Concluding remarks}

It should be clear by now that I am not arguing against logic per se. But what makes logic a distinct enterprise is its departure from natural reasoning. Its use as a model reveals, as does any metaphor, important similarities, but it also masks important differences. The proposed distinction between pointing and iconic functions of natural connectors tries to capture how logical transformation and discourse work are bound together.

The distinction may also be helpful for other syntactic analyses. Any syntactic category is relational and the interpretative work of segmentation can be seen as based on the pointing function of categories, a pointing function which may explain determination as well as indeterminacy. It may help in particular to illuminate some aspects of oral discourse which appears not to respect in all cases the rule according to which any item corresponds to only one syntactic category, as recent work on socalled syntactic double-bind has shown (Frank 1982; Widmer 1982, 250-56).

This distinction may capture also the suggestion of Alain Berrendonner (1983) that there is an analogy between anaphora and connectors. Both show similar context-sensitivity with regard to the location and the type of the "fillers" of their pointing slots. The main difference, which Berrendonner neglected, is that the iconic function of anaphora is not transformational but substitutional. It concerns the extraction of identical aspects of material meanings and is hence truth conditional.

Of course, much work still has to be done. My aim was not to explore the whole domain, but mainly to emphasise that there is much more work involved in the semantic study of connectors than merely stating their truth tables. These items in fact supply important clues for the construction of sentence meaning; and although they are peculiar, their peculiarity does not lie in their context-freeness, but in the special way they organize and are organized by the ongoing flow of meaning 25 .

25 I am deeply obliged to Professor Bent Jacobsen who has struggled with this text in order to make my English readable. 


\section{Literature}

Anscombre, Jean-Claude (1973): "Même le roi de France est sage. Un essai de description sémantique." Communications 20. (40-82)

Anscombre, Jean-Claude \& Oswald Ducrot (1977): "Deux mais en français?" Lingua 43. (23-40)

Barwise, John \& Jon Perry (1983): Situations and Attitudes. Cambridge: M.I.T. Press.

Berrendonner, Alain (1983): “"Connecteurs pragmatiques" et anaphores." Cahiers de Linguistique Française 5. (215-246)

Blakemore, Diana (1987): Semantic Constraints on Relevance. Oxford: Basil Blackwell.

Burks, A.W. (1949): "Icon, Index, and Symbol." Philosophy and Phenomenological Research IX. (673-689)

Ducrot, Oswald (1980a): “Texte et énonciation." in: Ducrot et al.: les mots du discours. Les éditions de minuit. (7-56)

Ducrot, Oswald (1980b): “Analyses pragmatiques.” Communication 32. (11-60)

Ducrot, Oswald (1984): Le dit et le dire. Les éditions de minuit.

Frank, D. (1982): Sentences in conversational turns: a case of syntactic "double bind". $\mathrm{ms}$.

Frege, Gottlieb (1952): “On Sense and Reference.” in: Geach, P. \& M. Black (éds.): Translations from Philosophical Writings of Gottlieb Frege. Oxford: Basil Blackwell and Mott. (56-78)

Garfinkel, H. (1967): Studies in Ethnomethodology. Englewood Cliffs, N.J.: PrenticeHall.

Garfinkel, H. \& H. Sacks (1970): “On formal structure of practical actions." in: J.C. McKinney \& E.A. Tiryakian (eds.): Theoretical Sociology: Perspectives and Development. New York: Appleton-Century-Crofts. (337-376)

Gettrup, Harald \& Henning Nølke (1984): "Stratégies concessives: une étude de six adverbes français." Revue Romane 19. (3-47)

Givón, Talmy (1982): "Logic vs. pragmatics, with human language as the referee: toward an empirical viable epistemology." Journal of Pragmatics 6. (81-133)

Greenbaum, Sidney (1969): Studies in English Adverbial Usage. London: Longman.

Grice, H.P. (1975): "Logic and Conversation." in: P. Cole \& J.L. Morgan (eds.): Syntax and Semantics 3: Speech Acts. New York: Academic Press. (41-58)

Ingarden, R. (1929): "Bemerkungen zum Problem Idealismus-Realismus." in: Festschrift für E. Husserl. Jahrbuch für Philosophie und Phänomenologische Forschung. Halle. (153-190)

Kamp, Hans (1981): "Evènements, représentations discursives et référence temporelle." Langages 64. (39-65)

Karolak, Stanislaw (1988): "Foncteurs, opérateurs, connecteurs — analyse notionnelle." in: Henning Nølke (ed.): Opérateurs syntaxiques et cohésion discursive dans les langues slaves et romanes. Copenhagen: Erhvervsøkonomisk Forlag. (11-26)

Kleiber, Georges (1988): “Peut-on définir une catégorie générale de l'anaphore?" Vox Romanica 47. (1-13)

Leech, Geoffrey (1974): Semantics. Middlesex: Penguin Books.

Lyons, John (1977): Semantics. Cambridge: Cambridge University Press. 
Meulen, Alice G.B. ter (ed.) (1983): Studies in Modeltheoretic Semantics. Dordrecht: Foris Publications.

Moeschler, Jacques \& Nina de Spengler (1981): "Quand même: de la concession à la réfutation." Cahiers de Linguistique Française 2. (93-112)

Montague, Richard (1974): Formal Philosophy. Yale: Yale University Press.

Morris, C.W. (1938): "Foundations of the Theory of Signs." in: Neurath, O. R. Carnap \& C.W. Morris (eds): International encyclopaedia of unified science. Chicago: University of Chicago Press.

Nef, Frédéric (1988): Logique et langage. Essai de sémantique intensionnelle. Paris: Hermès.

Nølke, Henning (1982): "Problems in the semantic-pragmatic description of French adverbials like même, aussi, surtout and seulement." Acta Hafniensia 17. (59-71)

Nølke, Henning (1983): Les adverbes paradigmatisants : fonction et analyse. Revue Romane Numéro Spécial 23. Copenhagen: Akademisk Forlag.

Nølke, Henning (1989): Polyfoni : En sprogteoretisk indføring. ARK 48. The Business School of Copenhagen.

Nølke, Henning (1990a): "Pertinence et modalisateurs d'énonciation." Cahiers de Linguistique Française 11.

Nølke, Henning (1990b): "Il y a connecteurs et connecteurs : la connexion analytique et synthétique en français moderne." in: H. Stammerjohan (ed.): Analyse et synthèse dans les langues slaves et romanes. Tübingen: Gunther Narr.

Peirce, C.S. (1960): Collected Papers. Cambridge: Cambridge University Press.

Posner, Roland (1980): "Semantics and pragmatics of sentence connectives in natural language." in: John R. Searle et al. (eds.).

Ross, J.R. (1986): Infinite Syntax. Ablex Publishing Corporation.

Sacks, H. (1974): "On the analysability of stories by children." in: G. Psathas (ed.): Everyday Language. New York: Irvington. (15-21)

Searle, John R. (1978): “Literal Meaning.” Erkenntnis 18. (207-224)

Searle, John R. (1980): “The background of meaning.” in: John R. Searle et al. (eds.).

Searle, John R., Ference Kiefer \& Manfred Bierwisch (eds.) (1980): Speech Act Theory and Pragmatics. Dordrecht-Holland: Reidel.

Sperber, Dan \& Deidre Wilson (1986): Relevance. London: Blackwell.

Widmer, Jean (1982): "Placement et structuration: aspects interactionnels et linguistiques d'une intervention." Cahiers de Linguistique Française 4. (229-261)

Widmer, Jean (1983): "Remarques sur les classements d'âge." Revue Suisse de Sociologie 9. (337-364)

Wittgenstein, L. (1922): Tractatus logico-philosophicus. London. 
